\title{
Radialene Synthesis
}

\section{Key words}

tricyclobutabenzenes

ring opening<smiles>CCOC(=O)OCCOC(=CC(C)C)OCC</smiles>

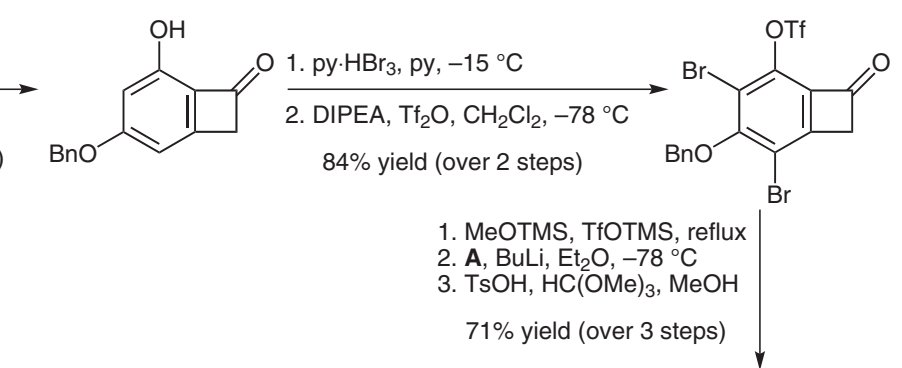

radialenes

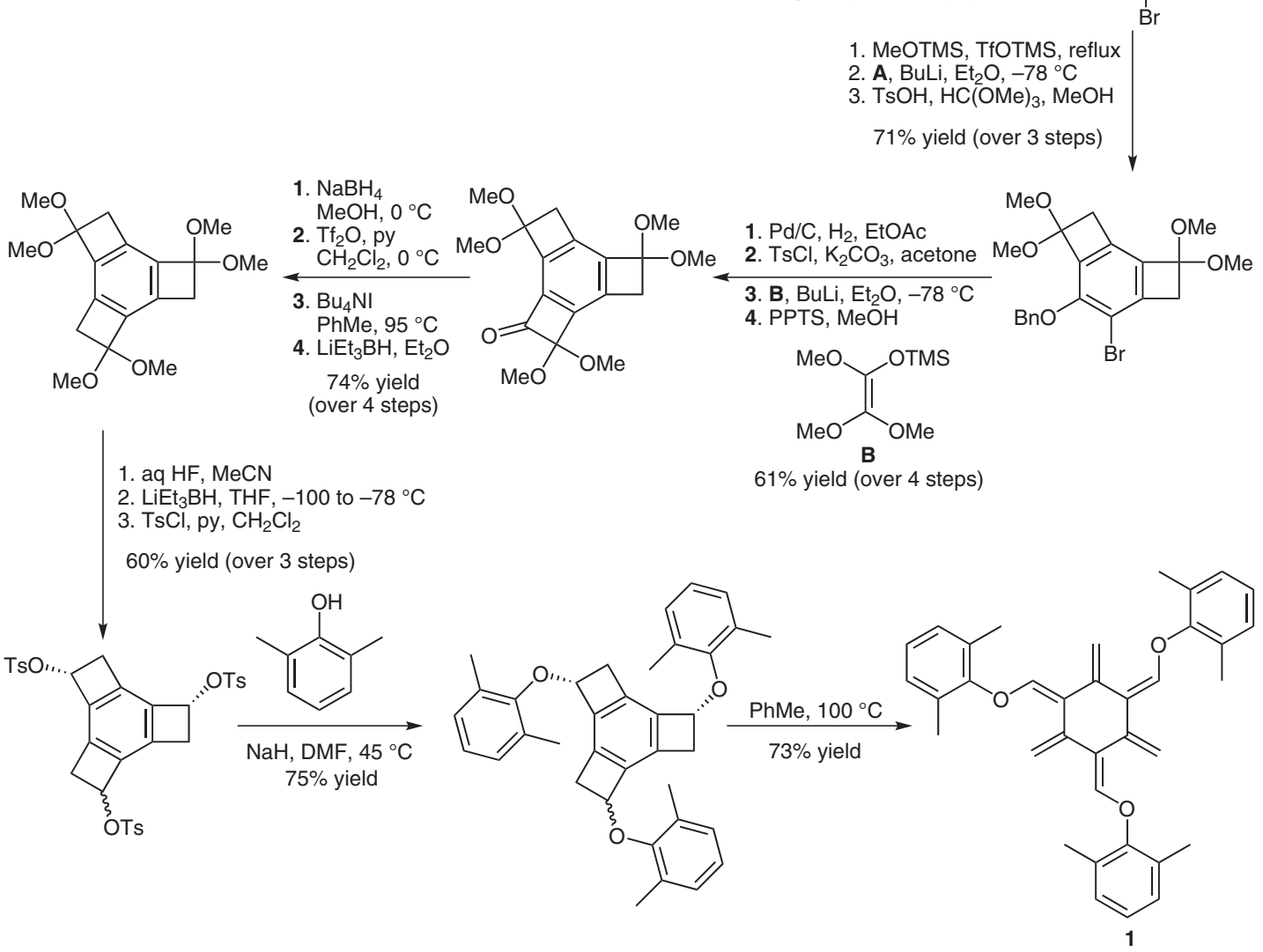

Significance: The authors present a remarkable synthetic route to hexaradialene $\mathbf{1}$ that utilizes a thermally-driven ring-opening isomerization reaction to form the six exocyclic double bonds in the final step. The reaction proceeds efficiently provided that sufficiently bulky groups are tethered to the triannulated parent compound prior to isomerization, with both the syn and the anti precursors converted into $\mathbf{1 .}$
Comment: Alicyclic cross-conjugated molecules of this type are rare and further studies on the reactivity of these intriguing molecules could provide new routes to novel polycyclic aromatic systems. 